\title{
Cell Therapy for Lung Disease: Current Status and Future Prospects
}

\author{
Sara Rolandsson Enes ${ }^{1,2} \cdot$ Daniel J. Weiss ${ }^{1}$
}

Published online: 15 May 2020

(C) The Author(s) 2020

\begin{abstract}
Purpose of Review Mesenchymal stromal cell (MSC)-based therapies provide a platform for new therapeutic strategies in lung diseases. This review provides an overview of the current status of the field, along with some of the challenges ahead including better understanding of MSC actions in different lung diseases, personalized approaches to select patients most likely to benefit, and the growing problem of stem cell tourism.

Recent Findings A newly evolving concept suggests that MSCs shape their immunomodulatory actions depending on the environment they encounter. Furthermore, in some models, it appears that dying or dead cells may contribute to the therapeutic efficacy by activating the host response.

Summary Despite many pre-clinical studies demonstrating that MSCs can be used to treat lung disorders, clinical trials have failed to show improved outcome. Understanding the complex interaction between MSCs and the host microenvironment is likely to be an important area for enhancing the efficacy of MSC-based cell therapies.
\end{abstract}

Keywords Mesenchymal stromal cells $\cdot$ MSC $\cdot$ Cell therapy $\cdot$ Microenvironment $\cdot$ Stem cell tourism

\section{Introduction}

Respiratory diseases remain a significant cause of morbidity and mortality worldwide, and for many of the severe lung diseases including idiopathic pulmonary fibrosis (IPF), chronic obstructive pulmonary disease (COPD), cystic fibrosis (CF), bronchopulmonary dysplasia (BPD), and acute respiratory distress syndrome (ARDS) there is currently no cure. Therefore, extensive efforts continue for development of new therapeutic strategies. The promising pre-clinical results using mesenchymal stromal cell (MSC)-based cell therapy in experimental lung disease models (reviewed in [1,2]), in combination with successful clinical trials in other diseases such as graft-versus-host-disease, have resulted in an increased

Sara Rolandsson Enes

sara.rolandsson_enes@med.lu.se

Daniel J. Weiss

Daniel.Weiss@med.uvm.edu

1 Department of Medicine, 226 Health Science Research Facility, Larner College of Medicine, University of Vermont, 149 Beaumont Avenue, Burlington, VT 05405, USA

2 Department of Experimental Medical Science, Faculty of Medicine, Lund University, Lund, Sweden interest and rapidly growing number of clinical trials using MSCs for a range of lung diseases and critical illnesses. MSCs are multipotent cells with immune-modulatory and regenerative properties, and in combination with their low or absent constitutive HLA class I and II expression, they are theoretically ideal candidates to be used in cell-based therapies, (reviewed in [3, 4]). In this review, we summarize the current status of the field of MSC therapies, highlight new discoveries about the role of the microenvironment in control of MSC therapeutic behaviors, and discuss the current challenges that need to be overcome in order to provide clinical benefit in patients with lung diseases.

\section{MSC-Based Therapy in Lung Diseases: Where Do We Stand?}

The enthusiasm for using MSCs as a cell-based therapy was raised by encouraging pre-clinical in vivo data leading to the first clinical trial using MSCs as therapy for hematologic malignancies by Lazarus et al. in 1995 [5] and has further translated into clinical trials for several different acute and chronic lung diseases. Searching on the ClinicalTrials.gov database for trials listed through November 27, 2019 using the keywords "lung diseases" and "mesenchymal stromal cell" or "stromal cell" or "mesenchymal stem cell", or "pulmonary 
disease" and "mesenchymal stromal cell" or "stromal cell" or "mesenchymal stem cell" identified 77 human clinical trials, of which 68 are for patients with lung disease. So far, 19 of the studies have been completed with 11 of them having published results in the PubMed database, 3 are currently active trials, 22 are open and in the process of recruiting their first patient, 7 are not yet recruiting, 13 have unknown status, and 4 of the trials have been withdrawn or terminated [6] (Table 1). In this section, we will summarize and discuss some of the clinical studies that have been completed and highlight a few promising currently ongoing studies.

\section{Acute Respiratory Distress Syndrome}

Despite an increased understanding of the pathology and current advances in supportive care, morbidity and mortality remain high in patients with acute respiratory distress syndrome (ARDS) [7]. ARDS pathology is driven by an acute severe inflammatory response, and acknowledging that the general hypothesis is that MSCs mainly act as immunomodulatory cells via rapid-acting paracrine effects, ARDS could be an ideal target for MSC-based therapies. This assumption is further supported by pre-clinical studies demonstrating that MSC-based therapy is beneficial in experimental models of ARDS (reviewed in [8, 9]).

In 2014, MSC-based treatment entered clinical trials for ARDS patients. In this trial, allogeneic adipose-derived MSCs were administered to 12 ARDS patients (one single dose of MSCs $\left(1 \times 10^{6}\right.$ cells $\left./ \mathrm{kg}\right)$ or saline IV) [10]. A subsequent phase 1 dose-escalation safety trial (START trial, NCT01775774) using a single dose of allogeneic bone marrow-derived MSCs at 1.0, 5.0, and $10.0 \times 10^{6}$ cells per $\mathrm{kg}$ of predicted bodyweight in 9 ARDS patients was conducted [11]. These two trials were early phase 1 studies with the primary outcome being safety and were both underpowered to detect significant differences in efficacy. Both trials showed that MSCs were well tolerated in ARDS patients. While no significant differences in efficacy were observed, in the START study changes observed in the Sequential Organ Failure Assessment (SOFA) score and Lung Injury score (LIS) with the high dose of $10.0 \times 10^{6} \mathrm{MSCs} / \mathrm{kg}$ were promising. This led to a randomized phase 2 a safety trial (NCT02097641) in which patients with moderate to severe ARDS received a single dose of the higher concentration $\left(10.0 \times 10^{6} \mathrm{MSCs} / \mathrm{kg}\right)$ of bone marrow-derived MSCs. Similar to the first trial, no safety issues were observed but no significant improvement in 28-day mortality was observed between the MSC treated group and the placebo group [12]. The authors reported that the patient group receiving the MSC treatment were more severely ill compared with the placebo group. However, there were no differences in SOFA between MSC- or placebo-treated groups in SOFA when assessed at either 3, 7, or 14 days. Also, an unexpected finding was that many of the MSC batches had a very low post-thaw viability at the time of injection, which was speculated to have contributed to the lack of efficiency. However, as discussed further below, a new evolving concept suggests that dead or dying MSCs might be beneficial. More encouraging results were observed in a case study describing two patients with severe refractory ARDS who each received systemic administration of allogeneic bone marrow-derived MSCs $\left(2 \times 10^{6} \mathrm{MSCs} / \mathrm{kg}\right)$ on a compassionate use basis [13]. In contrast to previous studies, rapid significant clinical improvements occurred with both patients surviving and eventually being discharged from the hospital. Moreover, in a recent industry-sponsored trial, the company Athersys Inc. recently (May 2019) published a press release in which they announced positive results at 28 days of follow-up in their randomized, placebo-controlled, phase 1/2 ARDS (MUST-ARDS) trial using IV administration of an adult stem cell product named MultiStem ${ }^{\mathrm{R}}$ [14••]. MultiStem $^{\mathrm{R}}$ is composed of multipotent adult progenitor cells (MAPCs) obtained from adult bone marrow and expanded in adherence cultures. The MAPCs share some but not all attributes of MSCs utilized in the START study of from adult bone marrow, but they claim that cells are not the same as MSC. The key efficacy endpoint was met with a decreased mortality rate in the MultiStem ${ }^{\mathrm{R}}$ group $(4 / 20=25 \%)$ compared with the placebo group $(4 / 10=40 \%)$. With these positive results, it will be exciting to learn the results of other ongoing clinical trials (Table 1).

\section{Bronchopulmonary Dysplasia}

Bronchopulmonary dysplasia (BPD) remains a major contributor to mortality and morbidity in infants born prematurely, and current strategies to prevent this disease have been only moderately successful. BPD is a multifactorial disease where none of the current treatment strategies has effectively decreased complications in BPD survivors. Over the past years, the interest in using MSC-based therapies to treat BPD has increased especially in response to findings in pre-clinical studies demonstrating positive benefits $[15,16]$. Currently, there are several clinical trials for BPD registered as completed or active on ClinicalTrials.gov (Table 1). The first published trial using MSCs to treat infants with BPD was a phase 1, dose-escalation trial (NCT01297205) using umbilical cord blood-derived MSCs at a concentration of $1 \times 10^{7}$ or $2 \times 10^{7}$ cells per $\mathrm{kg}$ [17]. This study demonstrated that the treatment was well tolerated in patients with BPD and that the levels of IL-6, IL-8, MMP-9, TNF- $\alpha$, and TGF- $\beta$ in tracheal aspirates were significantly reduced compared with baseline values. A 2-year follow-up study of this trial (NCT01632475) was published in 2017 [18], revealing that although one infant in the MSC group died suffering from Enterobacter cloacae sepsis, the remaining 8 infants showed no sign of transplant-related adverse outcomes or tumorigenicity was observed [18]. In 


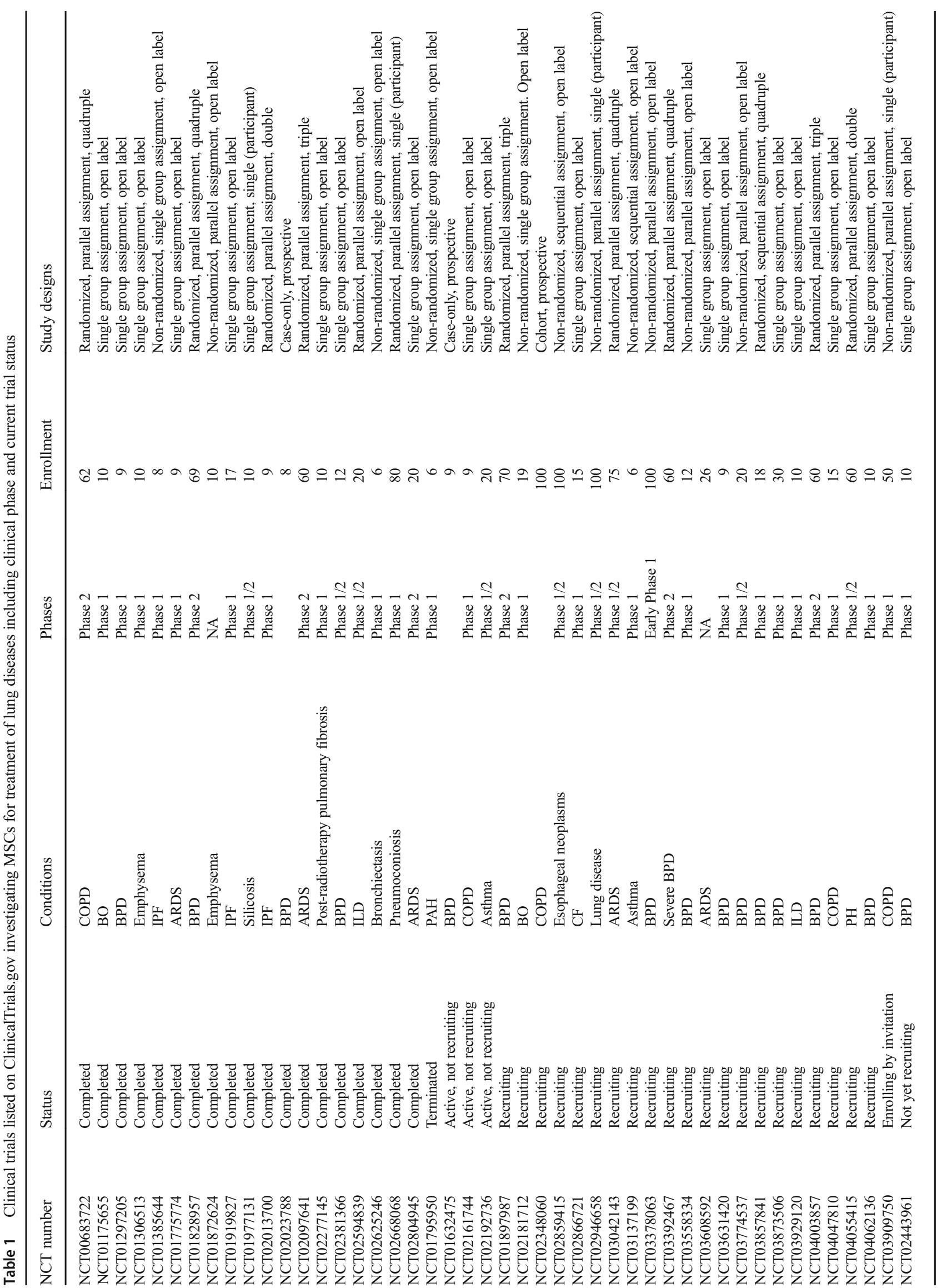




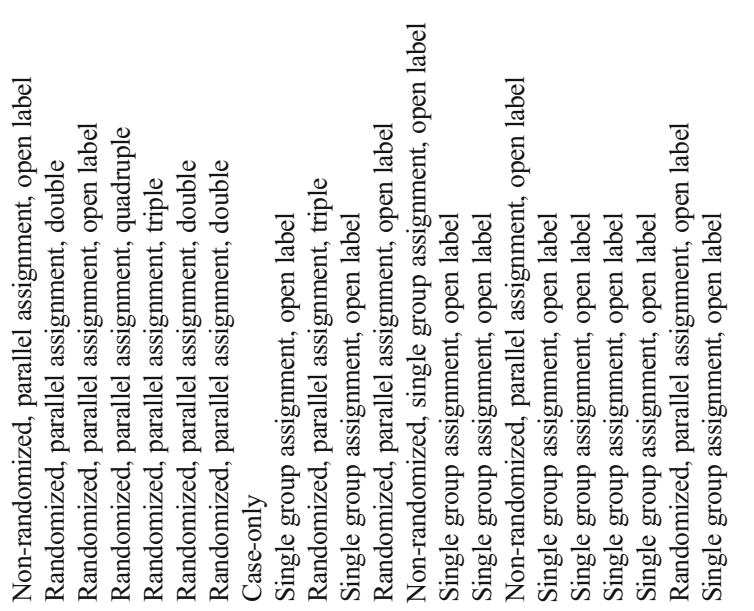

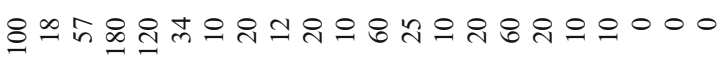

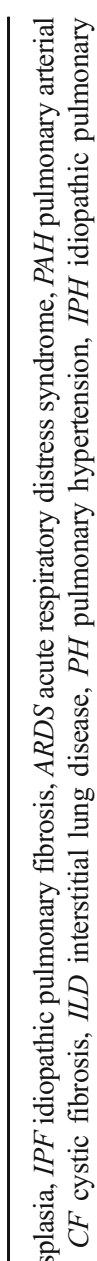

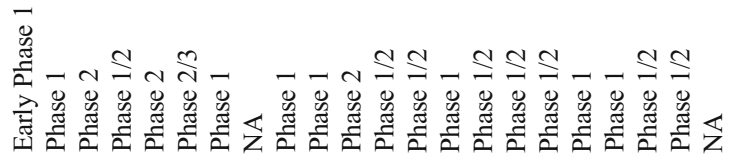

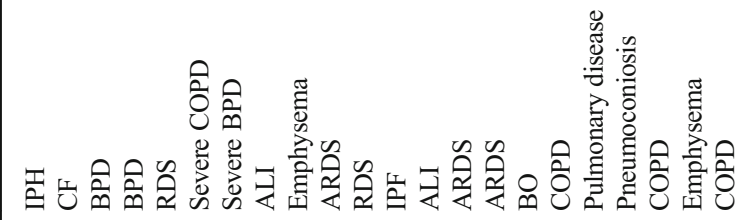

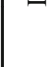

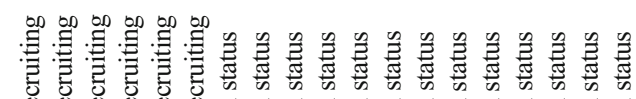

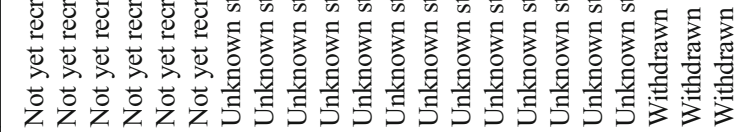

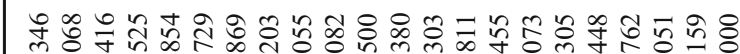

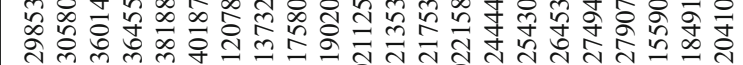

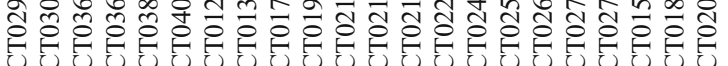

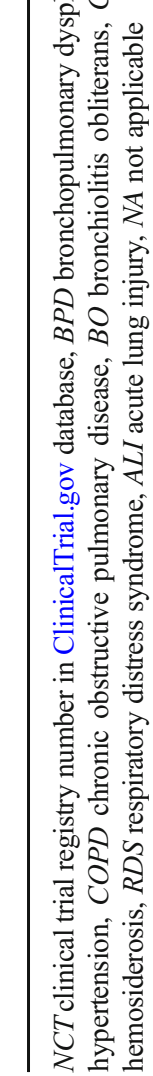


addition, this follow-up study reported decreased need for supplemental oxygen at discharge compared with the control group; however, larger trials are needed in order to prove efficacy. The same investigators are currently running a 5year follow-up study of the NCT01297205 trial (NCT02023788) as well as a phase 2 study (NCT01828957). Moreover, there is one additional clinical trial listed on ClinicalTrial.gov as completed (NCT02381366); however, there are no results yet published on the PubMed database from this trial. Taken together, the enthusiasm for MSC-based strategies for treatment of premature infants with BPD is currently increasing and at present, there are 9 clinical trials recruiting patients (Table 1).

\section{Chronic Obstructive Pulmonary Disease and Pulmonary Emphysema}

Chronic obstructive pulmonary disease (COPD) is a progressive life-threatening disease, which has a massive impact on public health and is currently increasing in prevalence. COPD is a complex pathology with several clinical phenotypes involving different degrees of inflammation, tissue damage, and structural changes. Current treatments are not curative and primarily consist of strategies to delay disease progression [19-22]. In pre-clinical (rodent) models (reviewed in [23]), systemic MSC administration has been variably demonstrated to improve inflammation and histologic lung structure. These promising data led to clinical trials for COPD and emphysema. The first trial using MSCs to treat COPD (NCT00683722) was performed in 2013 [24]. This investigation demonstrated the safety of using non-HLA-matched bone marrow-derived MSCs in an older patient population with moderate-to-severe COPD. Additional studies have since been performed using both systemic and direct airway delivery approaches and have demonstrated similar results of safety of MSC administration to COPD patients [25, 26, 27•]. However, none of these studies has demonstrated efficacy for treating COPD. Concerns with MSC have been whether or not the cells survive in vivo after administration to patients, and whether they could access sites of injury. In a recently published phase 1 study (Australian clinical trials registry number 12614000731695), MSCs were radiolabeled with indium-111 prior infusion. As in previous trials, all COPD patients tolerated the MSC infusions well. Interestingly, within $30 \mathrm{~min}$ the pre-labeled cells were detected in the lungs where they remained detectable for $24 \mathrm{~h}$. Moreover, the amount of positive labeling correlated with the diffusing capacity of the lung for carbon monoxide as well as with the baseline FEV1 [27•]. This study demonstrates that the third-party MSCs survive and diffuse throughout the lung to the same extent as carbon monoxide gas. Currently, there are four trials listed on ClinicalTriagerls.gov as active or recruiting participants with COPD (Table 1). These studies will hopefully reveal if COPD is suitable for
MSC-based therapy either as the main treatment or in combination with other relevant therapies.

\section{Idiopathic Pulmonary Fibrosis}

Idiopathic pulmonary fibrosis (IPF) is a life-threatening, progressive fibrotic lung disease of still poorly understood etiology. It has a patchy pathology with areas of massive deposition of extracellular matrix components, leading to reduced lung function. Currently, there are no curative treatments and in severe stages of the disease lung transplantation remain the only option [28]. MSC-based strategies have been extensively investigated in pre-clinical bleomycin-induced and other models of fibrotic lung injuries (reviewed in [29]). Despite the lack of convincing pre-clinical data on established lung fibrosis, early-phase clinical trials have been completed (Table 1). In 2013, Tzouvelekis et al. demonstrated in a prospective, non-randomized, no placebo-controlled phase 1 study that adipose-derived MSC were safe to give to IPF patients with no adverse events detected [30]. In a doseescalation phase 1 study (NCT01385644), Chambers et al. demonstrated that it was safe to inject placenta-derived MSCs at either $1 \times 10^{6}$ or $2 \times 10^{6}$ cells $/ \mathrm{kg}$; however, this study was not powered to detect efficacy [31]. In 2017, Glassberg et al. published the results from the AETHER study (NCT02013700) where they used a single dose of bone marrow-derived MSCs at $20 \times 10^{6}, 100 \times 10^{6}$, or $200 \times 10^{6}$ cells per infusion. This non-randomized and non-placebo controlled study included 9 patients, and while a few serious adverse events were reported, none was determined to be related to the MSC treatment. Similar to the other MSC trials, this study was not powered to detect efficacy, and no significant improvement in outcome was reported [32]. Taken together, clinical trials to date have shown safety and feasibility, but not benefit. Considering the general hypothesis that MSCs mainly act through rapid paracrine immunomodulatory mechanisms, advanced stages of IPF might not be the best suitable disease for MSC-based therapies.

\section{Current Challenges and Hurdles in the Field that Needs to Be Overcome}

MSC-based cell therapy for treatment of severe lung diseases has demonstrated promising results in experimental models; however, the lack of ability to translate these encouraging results into clinically relevant effects in patients has hampered the progression of the field. Despite an enormous interest in using MSCs for human clinical settings, the knowledge of MSC mechanisms of actions are limited and have predominantly been derived from pre-clinical studies $[4,33]$. A growing literature suggests that the MSC phenotype and in vivo functions differ from the basic in vitro understanding. For 
example, we and others have reported data suggesting that the in vivo mode of action changes depending on the inflammatory lung environment encountered [34•, 35•, 36••]. Moreover, MSCs exposed to the ARDS environment affects monocytes/macrophages by altering their phagocytic capacity and increasing anti-inflammatory M2 macrophage markers [35•]. In addition, Islam et al. recently demonstrated that the beneficial effect of MSCs was determined by the lung microenvironment. They further observed that high levels of both IL-6 and fibronectin in combination with low antioxidant capacity within the lung microenvironment resulted in poor outcome after MSC treatment in experimental lung injury [36••]. In addition, we recently demonstrated that MSCs stimulated with bronchoalveolar lavage fluid samples from patients with either ARDS or non-ARDS lung diseases exhibited both disease-specific and common MSC phenotypes [34•]. Taken together, the success of MSC-based clinical trials in lung diseases and other critical illnesses relies heavily on understanding the in vivo mode of action. Thus, a growing body of data suggests that the microenvironment within the diseased lung plays an important role in directing potential MSC therapeutic actions.

The generally accepted hypothesis has been that MSC therapeutic actions rely on the viability of the cells. However, this assumption has recently been challenged and recent studies suggest that dead or dying cells might improve the therapeutic effect by triggering host immune cells [37-40]. For example, administration of viable or heat-inactivated MSCs into an LPS induced lung injury mouse model evoked similar beneficial response [40]. More specifically, it is possible that systemically infused MSCs undergo apoptosis, which in turn activate the host immune system and lead to the immunomodulatory effects [37-40]. These are interesting data, however it is important to remember that these are xeno-transplantations (human into mouse), which may or may not contribute to these observations. The data on dead or dying MSCs in clinical trials are limited; nevertheless, a high portion of non-viable cells (85\%) was reported in a recent multicenter double-blinded randomized trial of systemic bone marrow-derived MSCs in ARDS patients [12]. No efficacy was observed in this trial suggesting that non-viable MSCs may not have clinical benefit in ARDS. There are currently relative few publications investigating the effects of dead or dying MSCs, and this needs to be further studied.

\section{Current Challenges and Hurdles for MSC Manufacturing for Clinical Applications}

Despite an increasing number of early phase clinical trials using MSC for lung diseases, there is at present no established scientific consensus concerning the source of origin of MSCs, dosing strategies, therapeutic dose, and cell product manufacturing (Table 2). MSC functionality changes depending on culture conditions including the isolation process, initial seeding density, number of passages, and culture surface. Despite this knowledge, a recent survey provided by the MSC committee of the International Society of Cell and Gene Therapy revealed that the current practice for manufacturing MSCs for clinical applications differs significantly in many of the above mentioned aspects amongst different US academic centers [41]. Although bone marrow was reported as the primary source of MSCs (93.3\% of the facilities), MSCs are also isolated from adipose tissue, umbilical cord, umbilical cord blood, and placental tissue. Not surprisingly, MSCs isolated from different sources have different phenotypes and secretome profiles [42-46]. Furthermore, the survey revealed that multiple different isolation strategies were utilized. For example, $46.7 \%$ of centers used enzymatic digestion, $26.7 \%$ used an automated system, and $13.3 \%$ used Ficoll gradient centrifugation or filtration. In addition, $93.3 \%$ reported plastic adherence as the main enrichment method, with only $6.7 \%$ reporting use of FACS sorting, immuno-depletion, or immune-enrichment strategies. Utilizing standard plastic culture dishes is the most frequent way of cultivating MSCs, however three-dimensional cell culture systems may narrow the gap between pre-clinical and clinical research. For example, culture dishes coated with extracellular matrix molecules such as fibronectin and collagen have been demonstrated to support MSC growth [47, 48]. In addition, changing the composition of the matrix proteins resulting in altered elasticity or stiffness has been demonstrated to alter MSC phenotype [49]. However, the majority of the centers (80\%) report using 2D culture methods with only three centers reporting exclusive use of 3D methods (bioreactor, bags, or hollow fibers) to expand MSCs. Also, seeding density affects MSC expansion and function. Fewer than $50 \%$ of centers report that they use low-density $\left(30 \%, 50-500\right.$ cells $\left./ \mathrm{cm}^{2}\right)$ or intermediate density $\left(16.7 \%, 500-2500\right.$ cells $\left./ \mathrm{cm}^{2}\right)$ meaning that the majority of facilities use a high plating density $\left(>2500\right.$ cells $\left./ \mathrm{cm}^{2}\right)$. The same wide variation in current practice in producing MSCs for clinical use has also been found in a similar survey performed on MSC manufacturing facilities in Europe [50].

In addition to the challenges discussed above, efforts to map out strategies to foresee which patient groups are most likely to respond to MSC-based treatments need to be made. Many of the experimental lung injury models used in preclinical studies have been optimized to detect maximum effects, and might therefore not reflect the truly in vivo situation (reviewed in [51]). A compelling amount of pre-clinical data suggest that MSCs can act by secretion of a spectrum of paracrine factors, and tracking studies of systemically administered MSCs have demonstrated that, following initial lodging of the majority of cells in the pulmonary vascular bed, the majority are cleared within a few days $[1,27 \bullet, 52]$. It is therefore unlikely that MSC-based treatments can remodel 


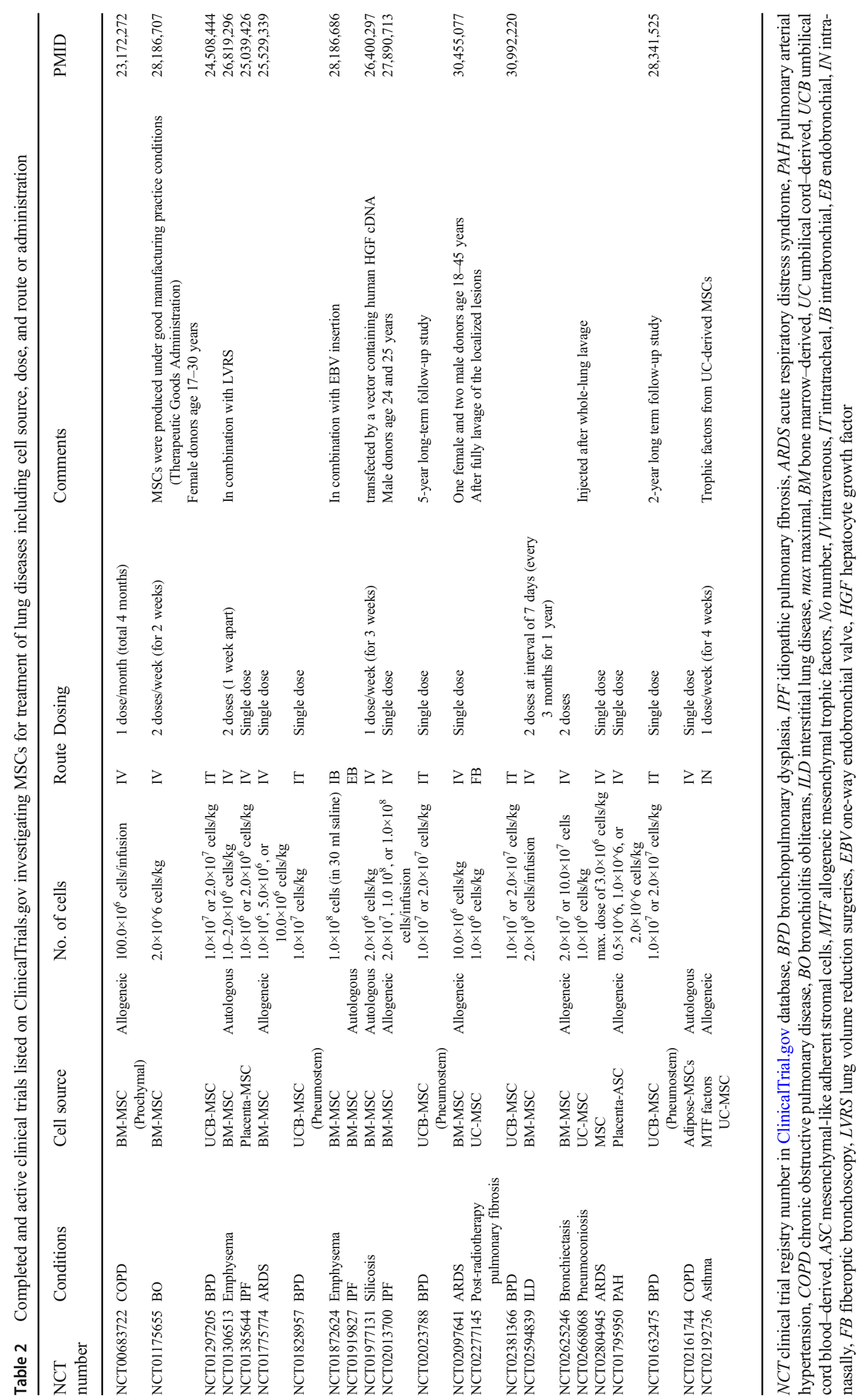


chronically injured and destroyed tissue such as found in advanced lung fibrosis or emphysema by differentiating into other cell types. Rather, it is more likely that MSC-based cell therapies will be more beneficial in diseases involving acute inflammation and infection such as ARDS and sepsis/septic shock. Moreover, ARDS is a multifaceted and heterogeneous disorder and there may be very meaningful differences in the host environment that will affect the therapeutic activity of MSCs. As such, we need to find strategies for selecting patients most likely to respond to the treatment. Another way to improve the clinical outcome would be to design MSC potency assays. However, without knowing the in vivo mode of action makes it difficult to determine what this assay or assays should be $[51,53]$. In addition, effort should also be made to optimize and unify outcome parameters measured in clinical trials for lung diseases in order to design successful clinical trials and to obtain maximum biologic and mechanistic information.

\section{Stem Cell Tourism}

In parallel with the progression of the field of cell-based therapies, a growing problem with commercial stem cell therapies has developed both in the USA and globally $[54,55]$. In modern life with daily access to internet and social media platforms, desperate patients, families, and caregivers can easily be misled into participating in very expensive and unproven stem cell treatments, which are not covered by insurance. Importantly, many stem cell clinics fail to prove safety and do not fulfill recognized biological and medical standards, exposing patients to unnecessary risks. These unethical clinics not only harm patients and their families, they also have the potential to hamper the progression of scientifically rigorous potential stem cell therapies. Therefore, the FDA, the International Society for Cell and Gene Therapies (ISCT), the International Society for Stem Cell Research (ISSCR) and an increasing number of respiratory disease foundations have taken stances against these stem cell clinics [56-62]. In an attempt to increase the knowledge about these clinics to patients, families, and caregivers, the American Thoracic Society (ATS) Respiratory Cell and Molecular Biology Assembly Stem Cell Working Group posted online statements and several other related publications [58-62]. In addition, earlier this year Google announced that they are not any longer accepting advertising for "unproven or experimental medical techniques such as most stem cell therapy, cellular (nonstem) therapy, and gene therapy" [63].

\section{Conclusions}

MSC-based therapies for severe lung diseases such as ARDS, COPD, IPF, and BPD have demonstrated promising results in experimental lung models; however, this has not translated into significant improved clinical outcome in patients to date. Importantly, current clinical trials have all demonstrated that MSC-based therapies are safe for lung disease patients; however, no significant efficacy or improved lung function has currently been demonstrated except for one promising investigation in patients with ARDS $\left[14^{\circ}\right]$. There are several challenges ahead for this field including revealing the in vivo mechanism of action, selecting the patient group most likely to respond, development of relevant potency assays, and the accelerating problem with the unethical stem cell clinics. Despite these challenges, there has been significant progression in the field and hopefully ongoing clinical trials will bring positive and encouraging clinical data with improved outcomes and hope for the future.

Funding Information Open access funding provided by Lund University.

\section{Compliance with Ethical Standards}

Conflict of Interest The authors declare no conflicts of interest.

Human and Animal Rights and Informed Consent This article does not contain any studies with human or animal subjects performed by any of the authors.

Open Access This article is licensed under a Creative Commons Attribution 4.0 International License, which permits use, sharing, adaptation, distribution and reproduction in any medium or format, as long as you give appropriate credit to the original author(s) and the source, provide a link to the Creative Commons licence, and indicate if changes were made. The images or other third party material in this article are included in the article's Creative Commons licence, unless indicated otherwise in a credit line to the material. If material is not included in the article's Creative Commons licence and your intended use is not permitted by statutory regulation or exceeds the permitted use, you will need to obtain permission directly from the copyright holder. To view a copy of this licence, visit http://creativecommons.org/licenses/by/4.0/.

\section{References}

Papers of particular interest, published recently, have been highlighted as:

- Of importance

-• Of major importance

1. Savukinas UB, Enes SR, Sjoland AA, Westergren-Thorsson G. Concise review: the bystander effect: Mesenchymal stem cellmediated lung repair. Stem Cells. 2016;34(6):1437-44.

2. Ryan AL, Ikonomou L, Atarod S, Bolukbas DA, Collins J, Freishtat $\mathrm{R}$, et al. Stem cells, cell therapies, and bioengineering in lung biology and diseases 2017. An Official American Thoracic Society Workshop Report. Am J Respir Cell Mol Biol. 2019;61(4):429-39.

3. Prockop DJ. Inflammation, fibrosis, and modulation of the process by mesenchymal stem/stromal cells. Matrix Biol. 2016;51:7-13. 
4. Galipeau J, Sensebe L. Mesenchymal stromal cells: clinical challenges and therapeutic opportunities. Cell Stem Cell. 2018;22(6): 824-33.

5. Lazarus HM, Haynesworth SE, Gerson SL, Rosenthal NS, Caplan AI. Ex vivo expansion and subsequent infusion of human bone marrow-derived stromal progenitor cells (mesenchymal progenitor cells): implications for therapeutic use. Bone Marrow Transplant. 1995;16(4):557-64.

6. ClinicalTrials.gov. 2018. https://clinicaltrials.gov. Accessed 27 Nov 2019.

7. Yadav H, Thompson BT, Gajic O. Fifty years of research in ARDS. Is acute respiratory distress syndrome a preventable disease? Am J Respir Crit Care Med. 2017;195(6):725-36.

8. Matthay MA, Pati S, Lee JW. Concise review: Mesenchymal stem (stromal) cells: biology and preclinical evidence for therapeutic potential for organ dysfunction following trauma or sepsis. Stem Cells. 2017;35(2):316-24.

9. Walter J, Ware LB, Matthay MA. Mesenchymal stem cells: mechanisms of potential therapeutic benefit in ARDS and sepsis. Lancet Respir Med. 2014;2(12):1016-26.

10. Zheng G, Huang L, Tong H, Shu Q, Hu Y, Ge M, et al. Treatment of acute respiratory distress syndrome with allogeneic adipose-derived mesenchymal stem cells: a randomized, placebo-controlled pilot study. Respir Res. 2014;15:39.

11. Wilson JG, Liu KD, Zhuo H, Caballero L, McMillan M, Fang X, et al. Mesenchymal stem (stromal) cells for treatment of ARDS: a phase 1 clinical trial. Lancet Respir Med. 2015;3(1):24-32.

12. Matthay MA, Calfee CS, Zhuo H, Thompson BT, Wilson JG, Levitt $\mathrm{JE}$, et al. Treatment with allogeneic mesenchymal stromal cells for moderate to severe acute respiratory distress syndrome (START study): a randomised phase 2a safety trial. Lancet Respir Med. 2019;7(2):154-62.

13. Simonson OE, Mougiakakos D, Heldring N, Bassi G, Johansson HJ, Dalen M, et al. In vivo effects of mesenchymal stromal cells in two patients with severe acute respiratory distress syndrome. Stem Cells Transl Med. 2015;4(10):1199-213.

14.• A. Inc, Athersys Presents Data From Its Acute Respiratory Distress Syndrome Clinical Trial at American Thoracic Society International Conference, 2019. The first press release announcing positive results with a decrease in mortality at 28 day followup in a randomized, placebo-controlled, phase $1 / 2$ ARDS trial using an adult stem cell product named MultiStem ${ }^{\mathrm{R}}$.

15. Augustine S, Cheng W, Avey MT, Chan ML, Lingappa SMC, Hutton B, et al. Are all stem cells equal? Systematic review, evidence map, and meta-analyses of preclinical stem cell-based therapies for bronchopulmonary dysplasia: Concise review. Stem Cells Transl Med. 2019

16. Nitkin CR, Rajasingh J, Pisano C, Besner GE, Thebaud B, Sampath $\mathrm{V}$. Stem cell therapy for preventing neonatal diseases in the $21 \mathrm{st}$ century: Current understanding and challenges. Pediatr Res. 2019.

17. Chang YS, Ahn SY, Yoo HS, Sung SI, Choi SJ, Oh WI, et al. Mesenchymal stem cells for bronchopulmonary dysplasia: phase 1 dose-escalation clinical trial. J Pediatr. 2014;164(5):966-72 e6.

18. Ahn SY, Chang YS, Kim JH, Sung SI, Park WS. Two-year followup outcomes of premature infants enrolled in the phase I trial of mesenchymal stem cells transplantation for bronchopulmonary dysplasia. J Pediatr. 2017;185:49-54 e2.

19. Mahboub BH, Vats MG, Al Zaabi A, Iqbal MN, Safwat T, AlHurish F, et al. Joint statement for the diagnosis, management, and prevention of chronic obstructive pulmonary disease for Gulf Cooperation Council countries and Middle East-North Africa region, 2017. Int J Chron Obstruct Pulmon Dis. 2017;12:2869-90.

20. W.H. Organization. Chronic obstructive pulmonary disease (COPD) fact sheet. WHO. 2016.
21. Mathers CD, Loncar D. Projections of global mortality and burden of disease from 2002 to 2030. PLoS Med. 2006;3(11):e442.

22. Westergren-Thorsson Gunilla BL, Oskar H. Extracellular matrix remodelling in COPD. Eur Med J (Nov). 2014:1-6.

23. Cruz FF, Rocco PRM. The potential of mesenchymal stem cell therapy for chronic lung disease. Expert Rev Respir Med. 2019: $1-9$.

24. Weiss DJ, Casaburi R, Flannery R, LeRoux-Williams M, Tashkin DP. A placebo-controlled, randomized trial of mesenchymal stem cells in COPD. Chest. 2013;143(6):1590-8.

25. Stolk J, Broekman W, Mauad T, Zwaginga JJ, Roelofs H, Fibbe WE, et al. A phase I study for intravenous autologous mesenchymal stromal cell administration to patients with severe emphysema. QJM. 2016;109(5):331-6.

26. de Oliveira HG, Cruz FF, Antunes MA, de Macedo Neto AV, Oliveira GA, Svartman FM, et al. Combined bone marrowderived mesenchymal stromal cell therapy and one-way endobronchial valve placement in patients with pulmonary emphysema: a phase I clinical trial. Stem Cells Transl Med. 2017;6(3): 962-9.

27. Armitage J, Tan DBA, Troedson R, Young P, Lam KV, Shaw K, et al. Mesenchymal stromal cell infusion modulates systemic immunological responses in stable COPD patients: a phase I pilot study. Eur Respir J. 2018;51(3) Demonstrates the biodistribution of allogeneic bone marrow-derived MSCs following intravenous infusion in COPD patients.

28. Raghu G, Collard HR, Egan JJ, Martinez FJ, Behr J, Brown KK, et al. An official ATS/ERS/JRS/ALAT statement: idiopathic pulmonary fibrosis: evidence-based guidelines for diagnosis and management. Am J Respir Crit Care Med. 2011;183(6):788-824.

29. Tzouvelekis A, Toonkel R, Karampitsakos T, Medapalli K, Ninou I, Aidinis V, et al. Mesenchymal stem cells for the treatment of idiopathic pulmonary fibrosis. Front Med (Lausanne). 2018;5:142.

30. Tzouvelekis A, Paspaliaris V, Koliakos G, Ntolios P, Bouros E, Oikonomou A, et al. A prospective, non-randomized, no placebocontrolled, phase $\mathrm{Ib}$ clinical trial to study the safety of the adipose derived stromal cells-stromal vascular fraction in idiopathic pulmonary fibrosis. J Transl Med. 2013;11:171.

31. Chambers DC, Enever D, Ilic N, Sparks L, Whitelaw K, Ayres J, et al. A phase $1 \mathrm{~b}$ study of placenta-derived mesenchymal stromal cells in patients with idiopathic pulmonary fibrosis. Respirology. 2014;19(7):1013-8.

32. Glassberg MK, Minkiewicz J, Toonkel RL, Simonet ES, Rubio GA, DiFede D, et al. Allogeneic human mesenchymal stem cells in patients with idiopathic pulmonary fibrosis via intravenous delivery (AETHER): a phase I safety clinical trial. Chest. 2017;151(5):971-81.

33. Martin I, Galipeau J, Kessler C, Le Blanc K, Dazzi F. Challenges for mesenchymal stromal cell therapies. Sci Transl Med. 2019;11(480).

34. Abreu SC, Enes SR, Dearborn J, Goodwin M, Coffey A, Borg ZD, et al. Lung inflammatory environments differentially alter mesenchymal stromal cell behavior. Am J Phys Lung Cell Mol Phys. 2019; This proof of concept study suggest that the inflammatory environment present in non-ARDS and ARDS patients have the potential to alter human bone marrow-derived MSCs functions.

35. Morrison TJ, Jackson MV, Cunningham EK, Kissenpfennig A, McAuley DF, O'Kane CM, et al. Mesenchymal stromal cells modulate macrophages in clinically relevant lung injury models by extracellular vesicle mitochondrial transfer. Am J Respir Crit Care Med. 2017;196(10):1275-86 Provides evidence that the inflammatory environment in ARDS patients modulate human MSC function on human macrophages partly through extracellular vesicle mitochondrial transfer. 
36.• Islam D, Huang Y, Fanelli V, Delsedime L, Wu S, Khang J, et al. Identification and modulation of microenvironment is crucial for effective mesenchymal stromal cell therapy in acute lung injury. Am J Respir Crit Care Med. 2019;199(10):1214-24 Provides evidence that the microenvironment in the recipient at the time of MSC administration will determine if MSC therapy will be beneficial or detrimental.

37. Weiss DJ, English K, Krasnodembskaya A, Isaza-Correa JM, Hawthorne IJ, Mahon BP. The necrobiology of mesenchymal stromal cells affects therapeutic efficacy. Front Immunol. 2019;10: 1228.

38. de Witte SFH, Luk F, Sierra Parraga JM, Gargesha M, Merino A, Korevaar SS, et al. Immunomodulation by therapeutic mesenchymal stromal cells (MSC) is triggered through phagocytosis of MSC by monocytic cells. Stem Cells. 2018;36(4):602-15.

39. Galleu A, Riffo-Vasquez Y, Trento C, Lomas C, Dolcetti L, Cheung TS, et al. Apoptosis in mesenchymal stromal cells induces in vivo recipient-mediated immunomodulation. Sci Transl Med. 2017;9(416).

40. Luk F, de Witte SF, Korevaar SS, Roemeling-van Rhijn M, Franquesa M, Strini T, et al. Inactivated mesenchymal stem cells maintain immunomodulatory capacity. Stem Cells Dev. 2016;25(18):1342-54.

41. Phinney DG, Galipeau J, C. Msc Committee Of The International Society Of, T. Gene. Manufacturing mesenchymal stromal cells for clinical applications: A survey of Good Manufacturing Practices at U.S. academic centers. Cytotherapy. 2019;21(7):782-92.

42. Rolandsson Enes S, Ahrman E, Palani A, Hallgren O, Bjermer L, Malmstrom A, et al. Quantitative proteomic characterization of lung-MSC and bone marrow-MSC using DIA-mass spectrometry. Sci Rep. 2017;7(1):9316.

43. Rolandsson Enes S, Andersson Sjoland A, Skog I, Hansson L, Larsson $\mathrm{H}$, Le Blanc $\mathrm{K}$, et al. MSC from fetal and adult lungs possess lung-specific properties compared to bone marrowderived MSC. Sci Rep. 2016;6:29160.

44. Pires AO, Mendes-Pinheiro B, Teixeira FG, Anjo SI, Ribeiro-Samy $\mathrm{S}$, Gomes ED, et al. Unveiling the differences of secretome of human bone marrow mesenchymal stem cells, Adipose TissueDerived Stem Cells, and Human Umbilical Cord Perivascular Cells: A Proteomic Analysis. Stem Cells Dev. 2016;25(14):107383.

45. Lama VN, Smith L, Badri L, Flint A, Andrei AC, Murray S, et al. Evidence for tissue-resident mesenchymal stem cells in human adult lung from studies of transplanted allografts. J Clin Invest. 2007;117(4):989-96.

46. Melief SM, Zwaginga JJ, Fibbe WE, Roelofs H. Adipose tissuederived multipotent stromal cells have a higher immunomodulatory capacity than their bone marrow-derived counterparts. Stem Cells Transl Med. 2013;2(6):455-63.

47. Salzig D, Leber J, Merkewitz K, Lange MC, Koster N, Czermak P. Attachment, growth, and detachment of human mesenchymal stem cells in a chemically defined medium. Stem Cells Int. 2016;2016: 5246584.

48. Somaiah C, Kumar A, Mawrie D, Sharma A, Patil SD, Bhattacharyya J, et al. Collagen promotes higher adhesion, survival and proliferation of mesenchymal stem cells. PLoS One. 2015;10(12): 0145068
49. Engler AJ, Sen S, Sweeney HL, Discher DE. Matrix elasticity directs stem cell lineage specification. Cell. 2006;126(4):677-89.

50. Trento C, Bernardo ME, Nagler A, Kuci S, Bornhauser M, Kohl U, et al. Manufacturing mesenchymal stromal cells for the treatment of graft-versus-host disease: a survey among centers affiliated with the European Society for Blood and Marrow Transplantation. Biol Blood Marrow Transplant. 2018;24(11):2365-70.

51. Galipeau J, Krampera M. The challenge of defining mesenchymal stromal cell potency assays and their potential use as release criteria. Cytotherapy. 2015;17(2):125-7.

52. English K. Mechanisms of mesenchymal stromal cell immunomodulation. Immunol Cell Biol. 2013;91(1):19-26.

53. Galipeau J, Krampera M, Barrett J, Dazzi F, Deans RJ, DeBruijn J, et al. International Society for Cellular Therapy perspective on immune functional assays for mesenchymal stromal cells as potency release criterion for advanced phase clinical trials. Cytotherapy. 2016;18(2):151-9.

54. Dominici M, Nichols K, Srivastava A, Weiss DJ, Eldridge P, Cuende N, et al. Positioning a scientific community on unproven cellular therapies: the 2015 International Society for Cellular Therapy Perspective. Cytotherapy. 2015;17(12):1663-6.

55. Dominici M, Nichols KM, Levine AD, Rasko JE, Forte M, O'Donnell L, et al. Science, ethics and communication remain essential for the success of cell-based therapies. Brain Circ. 2016;2(3):146-51.

56. Ikonomou L, Panoskaltsis-Mortari A, Wagner DE, Freishtat RJ, Weiss DJ, C. American Thoracic Society Respiratory, et al. Unproven stem cell treatments for lung disease-An emerging public health problem. Am J Respir Crit Care Med. 2017;195(7):P13-4.

57. Marks P, Gottlieb S. Balancing safety and innovation for cell-based regenerative medicine. N Engl J Med. 2018;378(10):954-9.

58. ATS RCMB Stem Cell Working Group. Statement on unproven stem cell interventions for lung diseases. New York: American Thoracic Society; 2016. https://www.thoracic.org/members/ assemblies/assemblies/rcmb/working-groups/stem-cell/resources/ statement-on-unproven-stem-cell-interventions-for-lung-diseases. pdf. Accessed Dec 2019.

59. Weiss DJ, Turner L, Levine AD, Ikonomou L. Medical societies, patient education initiatives, public debate and marketing of unproven stem cell interventions. Cytotherapy. 2018;20(2):165-8.

60. Ikonomou L, Freishtat RJ, Wagner DE, Panoskaltsis-Mortari A, Weiss DJ. The global emergence of unregulated stem cell treatments for respiratory diseases. Professional Societies Need to Act. Ann Am Thorac Soc. 2016;13(8):1205-7.

61. Ikonomou L, Wagner DE, Turner L, Weiss DJ. Translating basic research into safe and effective cell-based treatments for respiratory diseases. Ann Am Thorac Soc. 2019;16(6):657-68.

62. Wagner DE, Turner L, Panoskaltsis-Mortari A, Weiss DJ, Ikonomou L. Co-opting of ClinicalTrials.gov by patient-funded studies. Lancet Respir Med. 2018;6(8):579-81.

63. A new policy on advertising for speculative and experimental medical treatments, 2019. https://support.google.com/google-ads/ answer/9475042. Accessed Dec 2019.

Publisher's Note Springer Nature remains neutral with regard to jurisdictional claims in published maps and institutional affiliations. 